\title{
KAJIAN ANTROPOLOGI SASTRA DAN NILAI PENDIDIKAN DALAM CERITA RAKYAT KALANTIKA SERTA RELEVANSINYA SEBAGAI BAHAN AJAR DI SMP
}

\author{
Nurfitriana Maulidiah, Suyitno, Slamet Mulyono \\ Universitas Sebelas Maret \\ Surel: nmaulidiah@student.uns.ac.id
}

\begin{abstract}
This research is proposed to describe and explain; (1) the themes in folktale Kalantika, (2) the cultural features in activities of folktale's figure Kalantika, (3) the cultural result in folktale Kalantika, (4) the education value in set of folktale Kalantika,

(5) the relevance of set of folktale Kalantika with learning in Junior High School. This research used descriptive qualitative method with literary anthropology approach. Sampling technique that used in this research is purposive sampling. Collecting data technique use document analysis and interview. To validity the data, it uses triangulation of source. Data analysis technique in this research uses interactive analysis techniques. The results of this research shows that: (1) the themes of a set of folktale Kalantika were ideas about the human view of universe and knowledge system; (2) the cultural characteristic in activities of folktale's figure Kalantika were activities about equipment of human life, livelihood system, and knowledge system; (3) the cultural result of set of folktale Kalantika that can be find are the cultural result in the form of livelihood system and economy system, and knowledge system also; (4) education value that can be find are moral value, social value, religion value, and culture value; (5) Kalantika can be some teaching materials in literary learning of Junior High School.
\end{abstract}

Keywords: folktale, literary anthropology, themes, activities, cultural, education value

\begin{abstract}
Abstrak: Penelitian ini bertujuan mendeksripsikan dana menjelaskan; (1) tema-tema dalam cerita rakyat Kalantika, (2)ciri kebudayaan dalam aktivitas tokoh cerita rakyat Kalantika, (3) hasil budaya dalam cerita rakyat Kalantika, (4) nilai-nilai pendidikan dalam cerita rakyat Kalantika, (5) relevansi cerita rakyat Kalantika dengan pembelajaran di SMP. Penelitian ini merupakan penelitian deskriptif kualitatif dengan pendekatan antropologi sastra. Teknik analisis data dlam penelitian ini menggunakan teknik analisis interaktif. Hasil penelitian ini menunjukkan bahwa: (1) tema cerita rakyat Kalantika meliputi, ide tentang pandangan manusia dengan alam semesta dan ide tentang sistem pengetahuan; (2) ciri kebudayaan dalam aktivitas tokoh cerita rakyat Kalantika antara lain, aktivitas yang berhubungan dengan peralatan kehidupan manusia, aktivitas yang berhubungan dengan sistem mata pencaharian, dan aktivitas yang berhubungan dengan sistem pengetahuan; (3) hasil budaya cerita rakyat Kalantika yang dapat ditemukan adalah hasil budaya berbentuk mata pencaharian dan sistem ekonomi, serta hasil budaya berbentuk sistem pengetahuan; (4) nilai pendidikan yang ditemukan dalam cerita rakyat Kalantika adalah nilai pendidikan moral dan sosial(5) cerita rakyat Kalantika dapat dijadikan sebagai bahan ajar sastra di SMP kels VII.
\end{abstract}

Kata Kunci : cerita rakyat, antropologi sastra, ide, aktivitas, hasil budaya, nilai pendidikan.

\section{PENDAHULUAN}

Karya sastra merupakan hasil aktivitas manusia yang diwujudkan dalam bentuk yang indah, dengan memanfaatkan bahasa lisan maupun tulisan. Karya 
sastra lahir dari hasil kontemplasi penciptanya dan memiliki nilai yang akan hidup selama karya sastra itu terus berkembang.

Sebagai objek penelitian, karya sastra memiliki banyak dimensi, aspek dan unsur, yang dapat dikaji dengan berbagai macam teori dan metode. Selain itu, sastra dapat dikaji dalam penelitian multidisiplin seperti sosiologi sastra, psikologi sastra, dan antropologi sastra.Salah satu metode yang dapat digunakan dalam penelitian sastra adalah antropologi sastra.

Antropologi sastra meneliti perilaku yang muncul sebagai budaya dalam karya sastra. Menurut Endraswara (2013: 3), antropologi melihat semua aspek budaya manusia dan masyarakat sebagai kelompok variabel yang berinteraksi, sedangkan sastra diyakini merupakan cermin kehidupan masyarakat pendukungnya. Dalam konteks antropologi sastra, sastra adalah karya yang merefleksikan budaya tertentu.

Antropologi sastra merupakan salah satu disiplin ilmu yang termasuk baru diantara disiplin ilmu sastra lainnya. Hal ini sesuai dengan pernyataan Ratna (2011: 158) yang menyatakan bahwa antropologi sastra adalah kajian dengan menggabungkan hakikat karya sastra dengan antropologi merupakan model penelitian interdisiplin yang baru. Menurut Endraswara (2013: 1), antropologi sastra berupaya meneliti sikap dan perilaku yang muncul sebagai budaya dalam karya sastra. Manusia sering bersikap dan bertindak dengan tata krama. Tata krama memuat cara bersikap dan bahasa yang menjadi ciri sebuah peradaban. Sastra sering menyuarakan tata krama dalam interaksi budaya satu sama lain yang penuh simbol.

Hal ini senada dengan pendapat Nigel Rapport (dalam Máiréd, 2016) yang menjelaskan bahwa Literary anthropology can be understood here as an exploration of different kinds of genre of expression, and how these genres can be said to have a historical specificity, a cultural evaluation, and a social institutionalism attached to them.Dengan demikian, antropologi sastra memiliki tugas yang sangat penting untuk mengungkapkan aspek-aspek kebudayaan, khususnya kebudayaan tertentu masyarakat tertentu. 
Menurut Koentjaraningrat (2009: 150), terdapat tiga wujud kebudayaan yaitu (1) wujud kebudayaan sebagai suatu kompleks dari ide, gagasan, nilai, norma, peraturan dan sebagainya; (2) wujud kebudayaan sebagai suatu kompleks aktivitas serta tindakan berpola dari manusia dalam masyarakat; (3) wujud kebudayaan sebagai benda-benda hasil karya manusia.Koentjaraningrat (dalam Ratna, 2011: 74) menunjukkan tujuh ciri kebudayaan yang dapat digunakan untuk mengidentifikasi ciri-ciri antropologis yaitu peralatan dan perlengkapan kehidupan manusia, mata pencaharian dan sistem ekonomi, sistem kemasyarakatan, bahasa, baik lisan maupun tulisan, kesenian dengan berbagai mediumnya, sistem pengetahuan, dan sistem religi.

Abrams (Itadz, 2008: 69) menjabarkan bahwa cerita rakyat yang dalam bahasa Inggris disebut folktale adalah narasi pendek dalam bentuk prosa yang tidak diketahui pencitanya dan tersebar dari mulut ke mulut. Athaillah (1983: 3) menambahkan bahwa cerita rakyat adalah bagian dari folklore, yaitu karya sastra lisan yang berbentuk prosa. Dalam hal ini, Rampan (20114:1) ikut menjelaskan bahwa folklor bukan hanya berupa cerita rakyat yang disimpan di dalam berbagai bentuk cerita, melainkan meliputi juga berbagai hal lainnya seperti berbagai isyarat, alat pembantu pengingat, nyanyian, permainan anak-anak, peribahasa, cerita, teka-teki dan sebagainya yang dapat dilakukan secara verbal dan nonverbal.William R. Bascom (dalam Danandjaja, 1994: 50) menjelaskan bahwa cerita rakyat dibagi dalam tiga golongan besar yaitu mite (myth), legenda (legend), dan dongeng (folktale).

Cerita rakyat Kalantika ini berasal dari Kabupaten Sambas, Kalimantan Barat yang kurang dikenal masyarakatnya sendiri. Cerita rakyat yang dikumpulkan oleh Chairil Effendy di Kecamatan Sejangkung, Kabupaten Sambas. Melalui penelitian ini, diharapkan cerita rakyat Kalantika dapat dikenal oleh masyarakat dan relevan isinyasebagai bahan ajarsastra di tingkat SMP.

Sesuai dengan fungsinya sebagai sarana pembelajaran, di dalam setiap karya sastra terkandung nilai-nilai pendidikan. Pembaca harus mampu menafsirkan nilai-nilai pendidikan yang meliputi nilai keagamaan (religi), nilai moral, nilai sosial, dan nilai budaya. Di dalam "Dictionary of Philosophy" dari 
Dagobert D. runes (dalam Gusal, 2015) disebutkan bahwa nilai adalah sesuatu yang dihadapkan dengan kejadian yang nyata atau kehidupan nyata. Di sini sesuatu yang dihadapkan maksudnya ialah antara yang seharusnya dengan yang terjadi/terlaksana/berlaku, dan ukuran nilai tidak hanya digunakan untuk mengenai hal-hal dari bermacam-macam kebaikan, tetapi juga meliputi keindahan dan kebenaran. Dan masalah yang utama adalah hubungan antara nilai dan kehidupan.

Menurut Semi (dalam Sarumpaet, 2002: 134), kualitas pengajaran sastra yang dinilai rendah tentu saja dapat disebabkan oleh berbagai faktor seperti kurikulum, sarana belajar, dan guru. Cerita rakyat merupakan salah satu cara yang efektif untuk mengembangkan aspek-aspek kognitif (pengetahuan), efektif (perasaan), sosial, dan penghayatan anak-anak, selain itu cerita rakyat pun dapat membawa anak-anak pada pengalaman-pengalaman baru.Cerita rakyat merupakan bagian dari budaya Indonesia yang harus tetap dilestarikanagar bisa diminati oleh anak-anak sebagai sarana pembelajaran budaya dan nilai-nilai kearifan lokal. Mengangkat cerita rakyat sebagai bahan ajar di jenjang SMP merupakan salah satu upaya pemerintah untuk melestarikan cerita rakyat di masyarakat.

\section{METODE PENELITIAN}

Penelitian ini merupakan jenis penelitian deskriptif kualitatif dengan pendekatan antropologi sastra. Teknik pengambilan sampel dilakukan dengan mnggunakan purposive sampling. Data yang digunakan dalam penelitian ini berupaungkapan-ungkapandalam cerita rakyat Kalantika dan wawancara dengan narasumber yaitu penulis, guru bahasa Indonesia, dan siswa kelas VII SMP. Sumber data penelitian ini adalah dokumen dan informan.Teknik pengumpulan data menggunakan analisis dokumen dan wawancara. Validitas data menggunakan tringulasi sumber. Teknik analisis data dalam penelitian ini menggunakan teknik analisis interaktif yang terdiri dari empat tahap yaitu pengumpulan data, reduksi data, penyajian data, dan penarikan kesimpulan atau verifikasi. 


\section{HASIL PENELITIAN DAN PEMBAHASAN}

\section{Ide-ide dalam Cerita Rakyat Kalantika}

Sistem ide bersifat abstrak, terdapat pada ranah kognitif manusia. Menurut Koentjaraningrat (2009:151), ide dan gagasan manusia banyak yang hidup bersama dalam suatu masyarakat, memberi jiwa kepada masyarakat itu. Ide merupakan salah satu wujud budaya manusia di masa lampau yang bersifat tak benda. Ide yang dapat ditemukan dalam cerita ini adalah ide tentang pandangan manusia dengan alam semesta dan ide tentang sistem pengetahuan.

Ide tentang pandangan manusia dengan alam semesta berarti bagaimana manusia berperan di alam semesta. Manusia berusaha mencari keselarasan dengan alam dan membaca tanda-tanda yang diberikan alam untuk manusia. Pada akhir cerita disebutkan bahwa, "Maka, orang-orang di Kalimantan selalu menunggu kemunculan bintang Kalantika. Kalau bintang Kalantika sudah muncul barulah mereka mulai menanam padi" (Effendy, 2013: 7). Dari kutipan tersebut, tersirat ide tentang pandangan manusia terhadap alam semesta. Fenomena kemunculan bintang Kalantika dianggap sebagai tanda-tanda alam yang baik untuk menanam padi sekaligus menghormati Kalantika yang telah memberikan bibit padi kepada manusia.

Ide tentang sistem pengetahuan dalam pandangan ini membahas mengenai cabang-cabang pengetahuan dalam suatu kebudayaan. Menurut Koentjaraningrat(2009:291), tiap suku bangsa di dunia biasanya memiliki pengetahuan tentang alam sekitarnya; alam flora; alam fauna; zat-zat, bahan mentah, dan benda-benda dalam lingkungannya; tubuh manusia; sifat dan tingkah laku manusia; serta ruang dan waktu.

Dalam cerita rakyat Kalantika, manusia saat itu digambarkan dalam keadaan susah dan cenderung primitif. Namun disisi lain, manusia saat itu memiliki pengetahuan mengenai alam, flora dan fauna yang sangat baik. Seperti dalam kutipan berikut:

Pada masa itu makanan mereka pun sembarangan saja. Asal ada daundaun yang tidak membuat mabuk dimakan. Akar-akar kayu yang lembut dimakan. Buah-buahan hutan dimakan. Begitu juga macam-macam binatang yang ada di hutan mereka buuru dan tangkap untuk dimakan. 
Setelah mencari makan mereka masuk ke dalam gua-gua. Waktu itu hidup mereka di gua-gua. Pokoknya sederhana sekali hidup mereka (Effendy, 2013: 1).

Kutipan di atas menunjukkan bahwa manusia memiliki kemampuan untuk memilih daun-daun yang aman dimakan, akar-akar kayu dan buah-buahan di hutan yang dapat memenuhi rasa lapar mereka. Mereka mengetahui zat-zat yang terkandung dalam tumbuhan, sehingga dapat membedakan mana yang baik untuk dikonsumsi. Pengetahuan ini adalah pengetahuan dasar bagi manusia, terutama bagi mereka yang bermata pencaharian dalam pertanian dan berburu.

\section{Ciri Kebudayaan dalam Aktivitas Tokoh Kumpulan Cerita Rakyat Kalantika}

Ciri kebudayaan ini seringdisebut sistem sosial (social system) yang membahas tindakan berpola dari manusia itu sendiri. Sistem sosial ini terdiri dari aktivitas-aktivitas manusia yang berinteraksi, berhubungan, dan bergaul satu sama lain dari waktu ke waktu, selalu menurut pola-pola tertentu berdasarkan adat tata kelakuan.

Hasil analisis Cerita Rakyat Kalantika menunjukkan adanya aktivitas tokoh yang meliputiaktivitas yang berhubungan dengan peralatan kehidupan manusia, aktivitas yang berhubungan dengan sistem mata pencaharian, dan aktivitas yang berhubungan dengan sistem pengetahuan.

Pertama, aktivitas yang berhubungan dengan peralatan kehidupan manusia merupakan salah satu cerminan kemajuan suatu budaya.Menurut Koentjaraningrat (2009: 264-269) peralatan tersebut antara lain alat-alat produksi, alat membuat api, senjata, wadah, alat mengolah makanan, pakaian, tempat berlindung, dan alatalat transportasi.

Cerita rakyat Kalantika menceritakan manusia di masa lalu yang bertahan hidup dengan keterbatasan peralatan kehidupan mereka, seperti pakaian dan tempat berteduh. Hal ini dapat ditemukan pada paragraf pertama cerita rakyat Kalantika."...Mereka belum memiliki pakaian seperti sekarang. Mereka hanya menutupi tubuh mereka dengan daun-daun atau kulit kayu. Yang ditutupi pun hanya bagian-bagian tertentu saja....”(Effendy, 2013: 1). 
Pada masa lalu, manusia hanya menggunakan daun-daun atau kulit kayu untuk menutupi tubuh mereka. Mereka belum mengetahui proses pembuatan pakaian dari bahan tenun atau teknik pengolahan lainnya. Secara umum, pakaian mereka semata-mata sebagai alat untuk menahan pengaruh dari alam, seperti dingin dan panas.Selain cara berpakaian yang sangat sederhana, manusia pada masa itu juga tinggal di gua-gua seperti pada kutipan, "Setelah mencari makan mereka masuk ke dalam gua-gua. Waktu itu hidup mereka di gua-gua" (Effendy, 2013: 1). Berdasarkan kutipan tersebut dapat ditarik kesimpulan bahwa manusia pada masa itu masih sangat bergantung pada alam. Mereka mengandalkan hasil alam sebagai pakaian dan gua sebagai tempat tinggal.

Kedua, mata pencaharian dan sistem ekonomi merupakan wujud aktivitas manusia untuk memenuhi kebutuhan demi mempertahankan hidup. Manusia telah melewati berbagai fase dalam sistem ekonominya. Dalam cerita rakyat Kalantika ini, menceritakan manusia dalam fase berburu dan meramu hingga fase bercocok tanam di ladang. Seperti dalam kutipan berikut:

"Hei...," katanya kepada anak-anak di bumi, "mengapa kalian memakan daun-daun, akar-akar kayu, ranting-ranting kayu yang buruk?" "Memang inilah makanan kami di bumi ini," jawab anak-anak itu.

(Effendy,2013: 2-3)

Fase memburu dan meramu ini berubah seketika setelah Kalantika turun ke bumi dan membawa sebutir beras untuk diperlihatkan kepada manusia, seperti dalam kutipan "Lalu Kalantika dengan sembunyi-sembunyi turun ke bumi melalui batang cekur. Sesampainya di bumi padi itu diperlihatkannya kepada kawankawannya" (Effendy, 2013: 3-4).

Setelah Kalantika memperlihatkan beras kepada teman-temannya, ia pun menjelaskan bagaimana caranya menanam padi dan mengolahnya menjadi nasi.Pada tahap ini, kehidupan manusia berubah menjadi fase bercocok tanam di ladang. Mereka membuka sebidang tanah dengan memotong semak belukar dan pohon-pohon dan membakar sisa-sisa dahan yang ada di lahan untuk mengurangi 
keasaman tanah. Setelah padi mereka tumbuh subur, manusia kini memakan nasi. Seperti dalam kutipan berikut ini :

Begitulah kerja manusia setelah mendapat benih padi dari Kalantika. Padi mereka tumbuh subur, bagus. Mereka tidak lagi makan daun-daun, ranting-ranting, dan akar-akar kayu yang buruk. Mereka sudah memakan nasi. Cara menanak nasi pun diajarkan oleh Kalantika (Effendy, 2013: 5).

Berdasarkan paparan di atas, dapat disimpulkan bahwa cerita rakyat Kalantika memuat aktivitas sebagai wujud budaya manusia yang berhubungan dengan sistem mata pencaharian hidup. Mulai dari fase memburu dan meramu hingga fase bercocok tanam di ladang di lakukan oleh manusia untuk bertahan hidup.

Ketiga, aktivitas yang berhubungan dengan sistem pengetahuan merupakan aktivitas manusia yang berhubungan dengan pengetahuan manusia itu sendiri dan bersifat konkret, dapat diobservasi, difoto, serta didokumentasikan. Dari cerita rakyat Kalantika, sistem pengetahuan yang sangat menonjol adalah pengetahuan manusia mengenai alam sekitarnya, zat-zat bahan mentah dan benda di lingkungannya. Terdapat kalimat “....Abu pembakaran kayu-kayu itu dapat digunakan untuk mengurangi keasaman tanah...." (Effendy, 2013: 5). Dalam kalimat tersebut menyatakan bahwa manusia saat itu mengetahui kandungan dalam tanah dan manfaatnya bagi tanaman. Pengetahuan ini diperoleh manusia dari kalantika saat menjelaskan bagaimana caranya menanam padi. Untuk mengurangi tingkat keasaman tanah, mereka membakar ladang dengan dahandahan yang kering hingga dirasa cukup mengurangi tingkat keasaman tanah. Hingga saat ini, kebiasaan membakar ladang sebelum menugal masih dilaksanakan di Kalimantan.

\section{Hasil Budaya dalam Kumpulan Cerita Rakyat Kalantika}

Hasil budaya dalam kumpulan cerita rakyat Kalantika merupakan hasil fisik dan aktivitas, perbuatan, dan karya semua manusia dalam masyarakat. Bersifat konkret dan berupa benda yang dapat dilihat, difoto, dan diraba serta masih dipertahankan atau dilestarikan hingga saat ini.Dalam cerita rakyat Kalantika terdapat dua hasil budaya yang dapat diambil, yaitu kompleksitas hasil budaya 
berbentuk mata pencaharian dan sistem ekonomi, serta kompleksitas hasil budaya berbentuk sistem pengetahuan.

Pada awalnya, manusia bertahan hidup dangan cara memburu dan meramu. Setelah kedatangan Kalantika dengan berasnya, manusia kini bertahan hidup dan mencari nafkah dengan cara berladang. Seperti dalam kutipan, "Begitulah kerja manusia setelah mendapat benih padi dari Kalantika. Padi mereka tumbuh subur, bagus".(Effendy, 2013: 5).Pekerjaan berladang ini masih bertahan di beberapa daerah di Kalimantan Barat, terutama di Kabupaten Sambas. Komunitas masyarakat yang tinggal di Kabupaten Sambas menekuni berladang, sepertimenanam padi atau lada.

Kegiatan berladang masyarakat kaya akan sistem pengetahuan yang masih dipertahankan hingga saat ini.

"Padi ini harus ditanam dulu. Kalau dia sudah tumbuh nanti dia menjadi banyak, beranak pinak. Kalau sudah besar, sudah berisi, sudah masak, kulitnya menguning, baru diambil. Setelah dipanen dan ditumbuk barulah menjadi beras. Beras itulah yang dimasak untuk dimakan." Kata Kalantika menjelaskan kepada kawan-kawannya (Effendy, 2103: 3-4).

.... Mula-mula sedikit. Benih padi yang dibawa Kalantika ditanam. Dibuatlah tempat persemaian kecil. Eh ternyata tumbuh subur. Setelah cukup besar lalu manusia-manusia dibumi membuat ladang kecil mengikuti saran Kalantika.

Mereka menebang kayu-kayu, membersihkan tunggul-tunggul, membersihkan semak belukar. Lalu setelah itu mereka membuat saluran air agar tanah ladang mereka tidak keras. Setelah itu mereka menugal, membuat lubang-lubang untuk menanam padi. Setelah menugal barulah mereka menandur, menanam padi (Effendy, 2013: 4).

Karena bantuan dari Kalantika, akhirnya manusia dapat mengetahui bagaimana caranya menanam padi hingga mengolahnya menjadi nasi. Masyarakat mampu mengolah tanah gambut menjadi lahan yang baik untuk berladang melalui proses pembakaran ladang untuk mengurangi tingkat keasaman tanah. Hal ini sesuai dengan kutipan berikut.

Dari hari ke hari, bulan ke bulan, dan tahun ke tahun, ladang padi manusia semakin besar, semakin luas. Jadi, makin banyak pohon-pohon kayu besar yang ditebang, membuka lahan baru untuk menanam padi. Pohon-pohon, dahan-dahan, dan ranting-ranting kayu serta semak belukar harus dibakar. Abu pembakaran kayu-kayu itu dapat digunakan untuk mengurangi keasaman tanah. Makanya, orang-orang di Kalimantan ini berpindah-pindah berladangnya karena kalau abu hasil pembakaran sedikit, tingkat keasaman tinggi sehingga tanah tidak subur (Effendy, 2013: 5). 
Sistem pengetahuan mengenai alam semesta ini tidak diperoleh begitu saja, tetapi melalui proses pemikiran dan pengalaman manusia pada masa itu. Hingga saat ini, pembakaran hutan untuk pembukaan ladang di Kalimantan masih dilakukan, namun dengan pengawasan tinggi dari petani agar tidak merambat ke hutan dan semakin membesar.

Selain pengetahuan mengenai proses menanam dan persiapannya, pengetahuan manusia mengenai flora juga tidak diragukan. Hal ini dapat diketahui dalam kutipan:

Itulah sebabnya cekur berkhasiat karena dia menjadi tangga tempat Kalantika turun-naik ke bumi dan kayangan. Dia berkhasiat karena sudah kena tangan Dewa. Walaupun pohonnya kecil, tapi khasiatnya banyak. Untuk obat-obatan, untuk jamu, untuk bumbu masak, dan lain-lain (Effendy, 2013: 7).

Cekur atau kencur terkenal sangat berkhasiat bagi kesehatan. Dalam cerita rakyat ini, khasiat cekur diperoleh dari Kalantika yang menggunakan cekur menjadi satu-satunya akses ke bumi. Karena Kalantika adalah Dewa, maka ia menjadi berkhasiat. Namun karena ia telah disumpah oleh ayah Kalantika, maka ia berubah menjadi kecil namun tidak menghilangkan khasiatnya.

Setelah manfaat cekur, manusia diperkaya lagi dengan pengetahuan tentang alam sekitarnya. Mereka harus membaca tanda-tanda alam sebelum memulai menanam padi, seperti menunggu kemunculan bintang Kalantika. Hal ini dinyatakan pada kutipan:

Adapun Kalantika, lama-lama manusia di bumi tahu bahwa Kalantika sudah dikutuk oleh bapaknya menjadi batu. Kalantika yang dilemparkan bapaknya ke angkasa menjadi bintang Kalantika. Maka, orang-orang di Kalimantan selalu menunggu kemunculan bintang Kalantika. Kalau bintang Kalantika sudah muncul barulah mereka mulai menanam padi (Effendy, 2013: 7).

Kekayaan sistem pengetahuan yang dihasilkan dari cerita rakyat Kalantika masih diyakini dan dipertahankan hingga kini di Kabupaten Sambas sebagai salah satu khazanah kebudayaan Indonesia.

\section{Nilai Pendidikan dalam Cerita Rakyat Kalantika}

Nilai yang terkandung dalam karya sastra merupakan hal-hal yang dapat dijadikan sebagai acuan perilaku hidup dalam kegiatan sehari-hari. Sastra dan tata 
nilai kehidupan sebagai fenomena sosial saling berkaitan. Cerita rakyat Kalantika mengandung nilai pendidikan moral dan nilai pendidikan sosial yang dapat diteladani.

Pertama, nilai pendidikan moral dalam suatu karya sastra bertujuan untuk mendidik manusia untuk membedakan antara yang baik dan yang buruk. Dalam cerita rakyat ini, Kalantika merupakan sosok yang baik hati namun dalam beberapa kesempatan ia berbuat kurang terpuji walaupun bertujuan untuk menolong manusia.Kalantika mengambil sebutir padi secara diam-diam seperti dalam kutipan, "Suatu hari Kalantika turun lagi ke bumi. Sebelum turun dengan sembunyi-sembunyi dia masuk ke gudang penyimpanan beras bapaknya. Lalu diambilnya padi sebuah...." (Effendy, 2013: 3).

Tindakan Kalantika mengambil padi milik ayahnya secara sembunyisembunyi merupakan contoh yang kurang baik. Walaupun padi tersebut milik ayahnya, perbuatan tidak dibenarkan. Hendaknya ia meminta izin terlebih dahulu kepada ayahnya.Selain itu, wujud lain dari karakter moral yang kurang baik juga dimiliki oleh ayah Kalantika yang mengutuk Kalantika menjdi batu dan melemparkannya ke angkasa seperti dalam kutipan, "Kalantika, kau telah berbuat lancang. Mulai saat ini kau kukutuk menjadi batu." Lalu Kalantika menjadi sebongkah batu. Dewa kemudian mengambil batu itu dan melemparkannya ke angkasa" (Effendy, 2013: 6).

Cerita rakyat Kalantika ini terdapat nilai-nilai moral yang seharusnya tidak dilakukan oleh manusia. Peserta didik harus mendapatkan bimbingan dari guru agar tidak salah menarik nilai moral yang dapat dijadikan pelajaran.

Kedua, nilai pendidikan sosial mengacu pada interaksi sosial masyarakat yang terjalin. Dalam cerita rakyat Kalantika ini, sosok Kalantika diigambarkan sebagai dewa yang berjiwa sosial. Ia merasa iba dan heran melihat kehidupan di bumi seperti dalam kutipan, "Jadi Kalantika ini heran melihat kawan-kawannya memakan makanan yang tidak selayaknya" (Effendy, 2013: 2).Sifat sosial yang ditunjukkan Kalantika juga semakin diperkuat ketika ayahnya menanyakan alasan Kalantika mengambil bibit padi secara diam-diam yang diceritkan dalam kutipan,“Mengapa kau berikan bibit padi kepada manusia?” tanya Dewakepada 
Kalantika."Aku kasihan, Pak," jawab Kalantika" (Effendy, 2013: 6).Rasa iba yang muncul dalam diri Kalantika mencerminkan nilai sosial tinggi yang patut dicontoh oleh pembaca.

Relevansi Kumpulan Cerita Rakyat Kalantika dengan Pembelajaran Sastra di SMP

Sebelumdigunakansebagaibahan ajar, hendaknya dilakukan pemeriksaan kelayakan dari karya tulis tersebut. Kementrian Pendidikan dan Kebudayaan telah mengatur instrumen dan rubrik B3 untuk penilaian buku pengayaan kepribadian (Kemendikbud, 2014). Pada bagian dari Permendikbud Nomor 8 Tahun 2016 Tentang Buku yang Digunakan Oleh Satuan Pendidikan menguraikan kriteria kelayakan buku ke dalamlima kriteria yang harus dipenuhi sebagai buku yang layak digunakan di sekolah.

Yang pertama adalah materi mendukung pencapaian tujuan pendidikan nasional. Kumpulan cerita rakyat Kalantika dapat mendukung tujuan pendidikan nasional ditinjau dari cerita rakyat yang mengangkat kehidupan masyarakat Melayu pada masa lampau dan kental akan aktivitas keagamaan. Seperti kebiasaan Pak Pemancing pada cerita Putri Batu Karang, Putri Nyiur Gading, dan Putri Limau Manis yang selalu mengucapkan salam saat bertemu seperti dalam kutipan, “Assalamu'alaikum," kata Pak Pemancing memberi salam kepada Raja." (Effendy,2013:34). Kebiasaan ini pun dilakukan Pak Pemancing setiap menemui Raja. Kumpulan cerita rakyat Kalantika ini juga mengandung pembelajaran hidup serta nilai-nilai pendidikan yang mencakup nilai moral, nilai sosial, niali religi, dan nilai budaya yang dapat mendukung tercapainya tujuan pendidikan nasional.

Yang kedua yaitu materi tidak bertentangan dengan peraturan dan perundangundangan yang berlaku di indonesia. Dalam kumpulan cerita rakyat Kalantika, materi yang disajikan tidak menyimpang dari ketentuan dalam Pancasila, UndangUndang Dasar Tahun 1945, Undang-Undang Pornografi, Undang-Undang Perlindungan HAM, Undang-Undang Hak Cipta, dan undang-undang lain yang relevan. Hal ini dapat dilihat dari isi cerita yang dapat memberikan wawasan baru, namun dengan pendekatan cerita yang ringan dan dapat dikonsumsi dari semua 
umur. Dalam cerita Putri Jelumpang, usaha istri Raja untuk melindungi anaknya dapat dikaitkan pada Undang-Undang Nomor 23 Tahun 2002 Tentang Perlindungan Anak seperti dalm kutipan "Lalu istri raja memerintahkan kepada para hulubalang istana untuk membuat mahligai di atas pucuk pokok jelumpang. Hal ini dilakukan oleh istri Raja semata-mata untuk melindungi hak hidup Putri Jelumpang yang ingin dibunuh oleh Raja.

Ketiga, materi merupakan karya orisinal (bukan hasil plagiat), tidak menimbulkan sara, dan tidak diskriminasi gender. Kumpulan cerita rakyat Kalantika merupakan karya orisinal dan memiliki ISBN. Kumpulan cerita rakyat Kalantika ini mengangkat cerita dari masyarakat Melayu yang berada di Kabupaten Sambas, Kalimantan Barat tanpa membandingkan dengan suku lain yang dapat menimbulkan masalah SARA. Hal ini sejalan dengan Mantra (1980:46) yang menjelaskan bahwa SARA adalah berbagai pandangan dan tindakan yang didasarkan pada sentimen menyangkut keturunan, agama, kebangsaan atau kesukuan dan golongan.

Yang keempat, materi diuraikan secara mendalam dan memiliki kreativitas tinggi. Materi dalam kumpulan cerita rakyat Kalantika diungkap secara mendalam oleh penulis, sehingga dirasakan sebagai suatu karya yang bermanfaat bagi pembaca karena kedalaman isi karya tersebut. Salah satunya adalah saat Kalantika menjelaskan dan mengajarkan tahap-tahap berladang yang masih dipegang oleh masyarakat Melayu Sambas hingga saat ini seperti dalm kutipan," Padi ini harus ditanam dulu. Kalau dia sudah tumbuh nanti dia menjadi banyak, beranak pinak. Kalau sudah besar, sudah berisi, sudah masak, kulitnya menguning, baru diambil...."

(Effendy,2013:5). Karena kedalaman materi ini, buku ini dapat memenuhi kriteria sebagai materi pembelajaran apresiasi cerita rakyat terdapat pada jenjang kelas VII SMP dengan Kompetensi Dasar sebagai berikut. 


\begin{tabular}{|c|c|}
\hline KOMPETENSI DASAR KI 3 & KOMPETENSI DASAR KI 4 \\
\hline $\begin{array}{l}\text { 3.15 mengidentifikasi informasi } \\
\text { tentang fabel atau legenda daerah } \\
\text { setempat yang dibaca dan didengar. }\end{array}$ & $\begin{array}{l}\text { 4.15 Menceritakan kembali isi cerita } \\
\text { fabel/legenda daerah setempat yang } \\
\text { dibaca/didengar. }\end{array}$ \\
\hline $\begin{array}{l}3.16 \text { menelaah struktur dan kebahasaan } \\
\text { fabel atau legenda daerah setempat } \\
\text { yang dibaca dan didengar. }\end{array}$ & $\begin{array}{l}4.6 \text { memerankan isi fabel/legenda daerah } \\
\text { setempat yang dibaca dan didengar. }\end{array}$ \\
\hline
\end{tabular}

Selain itu, kumpulan cerita rakyat Kalantika dapat memberikan gambaran permasalahan hidup tokoh serta solusinya. Sehingga dapat dijadikan pembelajaran dan dapat menjadi teladan dalam kehidupan sehari-hari.

Yang kelima adalah materi membangun karakter bangsa indonesia yang mantap dan stabil. Kumpulan cerita rakyat Kalantika tidak bertentangan dengan ciri khas, nilai budaya, dan jati diri bangsa Indonesia. Materi mengenai cerita rakyat ini turut mengenalkan budaya dan jati diri bangsa kepada masyarakat dapat menghindari masuknya budaya asing yang tidak sesuai dengan kepribadian bangsa Indonesia. Hal ini sesuai dengan tujuan penerbitan kumpulan cerita rakyat Kalantika yang dikemukakan oleh Effendy (2013:xiii) yang menyatakan bahwa maksud dan tujuan penerbitan kumpulan cerita rakyat ini adalah agar khazanah kebudayaan Melayu dalam bentuk karya sastra ini dapat dibaca, dipelajari, dan dipahami serta ada nilai-nilai kearifan lokal yang dapat dipetik sebagai pelajarn untuk hidup di dunia modern yang semakin kompleks ini. Setelah dianalisis kelayakannya sebagai materi ajar, kumpulan cerita rakyat Kalantikarelatif memenuhi kriteria bahan ajar yang baik.

\section{SIMPULAN}

Berdasarkan hasil analisis data berupa cerita rakyat Kalantika, dapat disimpulkan bahwa cerita ini mengandung tema tentang pandangan manusia dengan alam dan sistem pengetahuan. Ciri kebudayaan yang menonjol terdapat pada aktivitas tokoh yang berhubungan dengan peralatan kehidupan manusia, aktivitas yang berhubungan dengan sistem mata pencaharian, dan aktivitas yang berhubungan dengan sistem pengetahuan. Cerita ini juga mengandung hasil budaya 
yang masih dipertahankan hingga saat ini berbentuk mata pencaharian dan sistem ekonomisertahasil budaya berbentuk sistem pengetahuan.

Nilai pendidikan dalam cerita ini adalah nilai pendidikan moral dan sosial. Cerita rakyat Kalantika ini layak digunakan sebagai bahan ajar di SMP berdasarkankriteria kelayakan buku berdasarkan Permendikbud nomor 8 Tahun 2016 yang diuraikan dalam Instrumen B3 tentang Penilaian Buku Pengayaan Kepribadian yang dikeluarkan oleh Kemendikbud pada tahun 2014.Pemanfaatan bahan ajar secara luas agar khazanah cerita rakyat di Indonesia tetap terjaga dan dilestarikan.

\section{DAFTAR PUSTAKA}

Athaillah. (1983). Cerita Rakyat Daerah Propinsi Daerah Istimewa Aceh. Jakarta: Depdikbud.

Badan Penelitian dan Pengembangan Pusat Kurikulum, Kementrian Pendidikan Nasional. (2014). Instrumen dan Rubrui B3 Penilaian Buku Pengayaan Kepribadian. Jakarta: Kementrian Pendidikan Nasional.

Craith, Máiréad Nic and L.S. Fournier. (2016). Literary Anthropology: The Subdisciplinary Context (Versi Elektronik). Antrhopological Journal of European Cultures, 04/ 2016, Volume 25, Issuue 1. Diperoleh pada 25 April 2017 dari http://eresources.perpusnas.go.id:2071/docview/1827831316/fulltextPDF/5F23F A3ACFA24CC5PQ/1? accountid=25704

Danandjaja, James. (1994). FOLKLOR INDONESIA: Ilmu Gosip, Dongeng, dan Lain-lain. Jakarta: Pustaka Utama Grafiti.

Effendy, Chairil. (2013). KALANTIKA. Pontianak: Pustaka Melayu Gemilang.

Endraswara, Suwardi. (2013). Metodologi Penelitian Antropologi Sastra. Yogyakarta: Penerbit Ombak.

Gusal, La Ode. (2015). Nilai-Nilai Pendidikan Dalam Cerita Rakyat Sulawesi Tenggara Kara La Ode Sidu(Versi Elektronik). Jurnal Humanika No. 15, Vol 3, Desember 2015. Diperoleh Pada 21 Februari 2017, Dari Http://Portalgaruda.Org/Article.Php?Article $=421486 \&$ Val=8476\&Title $=$ Nilai-Nilai\%20pendidikan\%20dalam\%20cerita\%20rakyat $\% 20$ sulawesi\%20tenggara\%20karya\%20la\%20ode\%20sidu 
Itadz. (2008). Memilih, Menyusun, dan Menyajikan Cerita Untuk Anak Usia Dini. Yogyakarta: Tiara Wacana.

Koentjaraningrat. (2009). Pengantar Ilmu Antropologi. Jakarta: Rineka Cipta.

Rampan, Korrie Layun.(2014). Teknik Menulis Cerita Rakyat. Bandung: Yrama Widya.

Ratna, Nyoman Kutha.(2011). Antropologi Sastra: Peranan Unsur-unsur Kebudayaan dalam Proses Kreatif. Yogyakarta: PT. Pustaka Pelajar.

Sarumpaet \& Riris K. Toha (ed). (2002). SASTRA MASUK SEKOLAH. Magelang: INDONESIATERA.

Sutopo, H.B.(2002). Metode Penelitian Sastra. Surakarta: UNS Press. 